\title{
Trailing Blackberries: From Clear-cuts to Your Table
}

\author{
Chad Finn ${ }^{1}$ \\ U.S. Department of Agriculture, Agricultural Research Service, Northwest Center for Small Fruit Research, 3420 \\ NW Orchard Ave., Corvallis, OR 97330
}

The commercial blackberry (Rubus sp.) industry in the United States and Canada can be roughly divided into eastern North America, Oregon, and California components. In the eastern United States, the plantings tend to be fairly small (mostly $<0.25$ ha, but up to $\approx 8$ ha), geared towards pick-your-own or local sales, with either semierect (e.g., 'Chester Thornless') or erect (e.g., 'Navaho') cultivars (Clark, 1992). In Oregon, there are $\approx 2500$ ha in production (National Agricultural Statistics Service-Oregon Agricultural Statistics Service, 1999), the crop is primarily machine-harvested for the processing market, and the cultivars are trailing types (e.g., 'Marion' and 'Thornless Evergreen'). The California blackberry industry, while still relatively small, is expanding, using publicly and privately developed trailing, erect, and semierect cultivars that are hand-harvested for wholesale, fresh-market sales. Breeding programs in Florida and Texas have developed blackberry cultivars from indigenous species, but have not accounted for a significant acreage in North America.

\section{BREEDING PROGRAMS}

While several breeding programs contributed to the development of blackberry cultivars, the bulk of the cultivars currently grown were developed by three programs. The U.S. Dept. of Agriculture (USDA) programs in Carbondale, Ill., and Beltsville, Md., have been the primary sources of the thornless, semierect cultivars, the most popular of which are 'Chester Thornless' and 'Hull Thornless', with 'Triple Crown' being the most recent. The Univ. of Arkansas program has been the source of the thorny and thornless erect cultivars, which include 'Navaho', 'Cherokee', 'Shawnee', and the recent releases 'Apache' and 'Chickasaw'. The USDA (Corvallis, Ore.), in cooperation with Oregon State Univ., has been the leading developer of the trailing blackberry cultivars, which include 'Marion', 'Olallie', 'Waldo', and the most recent releases, 'Black Butte' and 'Siskiyou'.

\section{ORIGIN OF CULTIVARS}

Each blackberry developed by these programs has distinct characteristics that can be traced to the species germplasm that was used when each program was begun. While the erect and semierect cultivars have very similar origins, the trailing blackberries are largely separate in origin (Hall, 1990). In Oregon, native selections of the western trailing blackberry (Rubus ursinus Cham. \& Schldl.) were used from the outset of the USDA blackberry breeding program in 1927 (Waldo, 1968). Eight wild selections, suspected to be hybrids of trailing blackberry and either 'Logan', a raspberry-blackberry hybrid, or another parent, such as 'Himalaya' ( $R$. armeniacus Focke; syn. R. procerus Muller), as well as 21 wild $R$. ursinus selections from California, Oregon, and Washington, were used in breeding between 1927 and 1994, when we began to use the material described in this paper. Among the wild selections, 'Zielinski', 'Santiam', and 'Hunter' were the most valuable parents (Waldo, 1950, 1968).

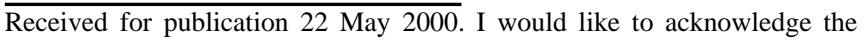
contributions of Angela Anderson and Rengong Meng, whose MS thesis research at Oregon State Univ. contributed to this paper; Kirsten Wennstrom (USDA-ARS/Oregon State Univ.) for overseeing the maintenance of the plant material and crosses discussed; Hugh Daubeny [Agriculture and Agri-Foods Canada, Agassiz, B.C. (retired)], Rick Harrison (Sweetbriar Inc., Watsonville, Calif.), and Ted Mackey (USDA-ARS) for help in collecting the bulk of the Rubus ursinus; and Jim Luby (University of Minnesota) for his inspiration in the initial conception of the work and help in collection of the plant material. The cost of publishing this paper was defrayed in part by the payment of page charges. Under postal regulations, this paper therefore must be hereby marked advertisement solely to indicate this fact.

${ }^{1}$ E-mail address: finnc@bcc.orst.edu
The raspberry-blackberry hybrids 'Logan' and 'Boysen', and the wild selection 'Santiam', served as a basis for the early Oregon industry and were also important in the breeding program (Waldo, 1968). 'Thornless Evergreen' (Rubus laciniatus Willd.) began to be widely planted in the mid-1900s and, while its fruit quality was only fair, it was reliable and productive (Waldo, 1977). 'Thornless Evergreen', a tetraploid apomictic genotype, has been used very little in breeding programs. The USDA in Corvallis has released a number of cultivars, including 'Pacific', 'Cascade', 'Chehalem', 'Olallie', 'Aurora', 'Kotata', 'Waldo', 'Black Butte', and 'Siskiyou', that have origins in $R$. ursinus. However, to date, 'Marion', which was released in 1956 (Waldo, 1957) and can be traced in large part to $R$. ursinus ancestry, has been the most significant release. 'Marion' began to account for significant acreage in the late 1960s, and was the most important blackberry cultivar in the world by the early 1980s (Finn et al., 1997). While renowned for its flavor and processing characteristics, 'Marion' is thorny, lacks winter hardiness, and has fruit that are too soft for easy handling.

\section{COLLECTION OF GERMPLASM}

Rubus ursinus is native from British Columbia to southern California, from the coast inland to the Cascade Mountains and east into Idaho (Hitchcock and Cronquist, 1973). It is dioecious and quickly colonizes any open areas, e.g., clear-cut or burned areas, from sea level to $\approx 2000$ $\mathrm{m}$. Our primary interest in systematically and thoroughly collecting $R$. ursinus was to find individuals or populations that had greater winter hardiness than was available in the breeding program. While many of the very cold areas are buried under $8 \mathrm{~m}$ of insulating snow each winter, $R$. ursinus exists in many areas that are colder than the commercial production areas of the Willamette Valley and that do not receive this amount of snowfall. In addition, we felt it would be valuable to expand our $R$. ursinus germplasm base with a more systematic approach rather than relying on the odd, unusual wild selections existing in germplasm collections at the time. Finally, the unique and valued flavor, flavor aromatics, and perceived lack of "seediness" of 'Marion' can be largely traced to $R$. ursinus. To expand our breeding material with selections that expressed these characteristics would be extremely valuable.

In 1993, Jim Luby and Rick Harrison from the Univ. of Minnesota and I collected small fruit germplasm in the state of Washington. The trip's primary goal was to collect Fragaria sp. and $R$. ursinus, but $R$. leucodermis Douglas ex Torrey \& A. Gray, Vaccinium membranaceum Douglas ex Torrey, V. ovalifolium Smith, and V. deliciosum Piper, as well as other fruit species, were also collected. These collections were concentrated on the Olympic Peninsula and the eastern and western slopes of the Cascade Mountains (Finn and Martin, 1996). To include $R$. ursinus representatives from throughout its northwest range, supplemental trips were made to the coast and coastal ranges in Washington and Oregon, the Siskiyou Mountains, and the Oregon Cascades. To fill gaps in our geographic range, seed populations were obtained from the National Clonal Germplasm Repository (NCGR), Corvallis, Ore., and from $\mathrm{H}$. Daubeny in British Columbia.

In total, 44 seed populations were assembled and, in addition, $\approx 25$ clonal cuttings were taken along a transect through each of 20 collection sites. Fruiting females of $R$. ursinus were collected whenever possible. Seedling populations were generated from the seed and the cuttings were rooted. Both groups of plants were established in the field or greenhouse.

\section{CHARACTERIZATION OF GERMPLASM}

Our research on this assembled collection had three primary focal points. First, these populations were characterized for vegetative and 
reproductive traits (Anderson and Finn, 1995a, 1995b, 1996). Second, a flow cytometry technique was developed to try to determine ploidy levels in the populations (Meng, 1999). Finally, the seedlings have been continuously evaluated to identify genotypes that would be useful for breeding.

To begin characterizing these populations, a greenhouse evaluation of 20 vegetative traits was begun in Dec. 1993, using rooted cuttings of 20 clonally collected populations (Anderson, 1995b). The plants were grown in a randomized block design with four replications. Ten genotypes from each population were potted and placed randomly within each replication along with 'Marion', 'Kotata', and 'Santiam' as controls. Seeds representing the 44 populations were scarified, stratified, and germinated to obtain seedling populations. In Spring 1994, up to 24 genotypes, representing each clonal population along with all of the seedlings, were planted into replicated plots at the NCGR Meyer Farm in Corvallis, Ore., and managed using standard commercial practices for trailing blackberries, without fungicide or insecticide applications. The genotypes were planted in a randomized complete-block design (four replications; 12-24 genotypes/population), with plots of 'Marion', 'Kotata', and 'Santiam' planted for comparison, and evaluated for 28 vegetative and reproductive traits. Analysis of variance was performed on all variables using SAS with PROC GLM, and principal component analysis was performed using PRINCOM (SAS Institute, 1995). The seedling populations were grown and selections made based on vigor, disease resistance, crop load, fruit size, and fruit quality.

The cultivars were excluded from the final analysis because they consistently acted as outliers. Regardless of the specific study, the populations had significant variation for most of the traits evaluated. Most of the variance in the principal component analysis could be accounted for by the first five principal components. A vigor component, which represented size and/or shape of leaves, canes, flower petals, and seeds, consistently accounted for the greatest amount of variance, from $49 \%$ to $69 \%$. When plots were used to visualize relationships among principal components and geographic factors, some generalizations could be made. The higher the elevation of the collection sites, the lower the vigor, the earlier the leaves senesced, the later the budbreak and fruit ripening, the shorter the fruit ripening interval and the smaller the fruit. As the collection sites moved from west to east, leaf senescence occurred earlier; however, this trend was somewhat confounded by the change in elevation from the Pacific Coast to the Cascade Mountains. The more southerly the populations, the earlier the budbreak, the longer from budbreak to first flower, and the greater the susceptibility to Septoria rubi Westend. In general, variability appeared to exist within these populations for all horticulturally important traits. In the future, we can target specific regions to increase the likelihood of successfully collecting genotypes with certain traits.

\section{Ploidy level}

The USDA program has utilized Rubus germplasm ranging in ploidy from $2 \mathrm{x}$ to $12 \mathrm{x}$ and has released cultivars that are $6 \mathrm{x}$ (e.g., 'Marion', 'Olallie', 'Black Butte'), 7x ('Kotata' and 'Siskiyou'), 8x+2 ('Aurora'), and 9x ('Cascade'). In order to better plan our crosses, we must know the ploidy level of our breeding material. While manual counting of chromosomes has proven to be reliable, we needed a method that was faster and cheaper. We developed a method of using flow cytometry (Meng, 1999), which was compared with the manual counting results reported by Thompson (1995a, 1995b, 1997). Flow cytometry proved to be effective in determining chromosome numbers differing by one set (e.g., 7x vs. 6x) and worked across all subgenera tested (Meng, 1999).

Subsequently we have used this technique on our $R$. ursinus collection. The range of ploidy for $R$. ursinus is reported as hexaploid to dodecaploid, although no septaploids have been reported (Brown, 1943). In addition, ploidy level differences have been used in part to separate $R$. ursinus into two separate species-8x types were considered to be $R$. ursinus and 12x types $R$. macropetalus Dough (Jennings, 1988). As part of Meng's (1999) work, two to five genotypes from 42 $R$. ursinus populations were analyzed. The ploidy levels of these genotypes predicted by flow cytometry ranged from $6 \mathrm{x}$ to $13 \mathrm{x}$, with $86 \%$ of the genotypes predicted to be $11 x, 12 x$, or $13 x$. Since we had no control genotypes available that were known to be $13 \mathrm{x}$, we cannot confidently extend our prediction equation to $13 x$. Currently, we are in the process of visually counting chromosomes of those genotypes that were predicted to be $13 x$ to determine if our prediction equation is valid for $13 x$. Those predicted to be $13 x$ could in fact be $12 x$. In addition, Meng (1999) found that different genotypes collected from the same site often had different ploidy levels. The range of ploidy levels, combined with the knowledge that these were all fertile, productive, female genotypes, suggests that we may be able to use these genotypes in a wide variety of crosses. We have begun to use them in various bridging schemes to incorporate $4 \mathrm{x}$ blackberry germplasm and germplasm from other subgenera into our breeding material.

Selections in these populations were made based on vigor, resistance to foliar disease, crop load, and fruit size. In addition, we attempted to keep at least two genotypes from each population. In comparison with our typical blackberry breeding material, the $R$. ursinus populations were: small-fruited ( $3-5 \mathrm{~g})$; early-flowering and -ripening; vigorous, with a greater number of small diameter canes; very susceptible to foliar disease; fertile; and soft-fruited. Some had excellent fruit flavor and eating quality. While nearly all of the selections were pistillate, male plants were also selected that covered the range of the flowering season from early to late. About 120 selections from the previously described seedling populations were planted in Corvallis, Ore., and at the Agriculture and Agri-Foods Canada research station in Abbotsford, B.C., for more detailed evaluation. The Abbotsford, B.C., site provided useful information because the climate is similar to that of the Willamette Valley but temperatures are 3 to $5^{\circ} \mathrm{C}$ colder in the winter.

\section{INCORPORATION OF GERMPLASM}

Based on performance at the various sites, we identified a number of promising parents and have made $\approx 110$ crosses using 30 different parents. Seedlings from our initial crosses were first evaluated in 1997 and 1998. The pollen parents were the trailing cultivars Black Butte $(6 x)$, Kotata (7x), Marion (6x), Waldo (6x), and Douglass (8x), and the semierect cultivars (all 4x) Chester Thornless, Dirksen Thornless, and Triple Crown. Of the trailing blackberries, 'Black Butte' and 'Waldo' produced the greatest number (37) and most interesting selections. 'Black Butte' was primarily used because of its very large fruit size, despite the fact that it lacks an intense flavor. 'Black Butte' is also one of the earliest-ripening trailing cultivars and R. ursinus, in general, is much earlier than any cultivar. As a result, a number of medium-large, productive, and very early-ripening (strawberry season) selections were made from this material. 'Waldo' is thornless, late-ripening, has medium-sized fruit with a high drupelet count per fruit (Strik et al., 1996), is resistant to foliar diseases, but lacks the aromatic flavor typified by 'Marion'. Selections from the crosses with 'Waldo' were excellent, producing highly flavored, medium-large fruit, often larger than the 'Waldo' parent, that ripened throughout the blackberry season on thornless canes. The fact that we have a range of ripening seasons in these thornless selections is very important because nearly all of the thornless genotypes in our program are mid- to late-season. The thornless character of 'Waldo' is derived from 'Austin Thornless', and selections from this source often have shortened internodes and brittle canes; none of the thornless selections from 'Waldo' $\mathrm{x} R$. ursinus crosses had these characteristics.

The crosses between the semierect blackberries, which are all $4 \mathrm{x}$, and the $8-12 \times 2$. ursinus were successful. Nine selections were made from crosses with 'Triple Crown'. These selections exhibited a full range of characters, but were usually semierect and excellent for vigor, disease resistance, fruit color and crop size, good for flavor and fertility, and poor for size, seediness, separation from the plant, and thorniness. While not of outstanding quality, these hybrids could facilitate exchange of genetic material between these two blackberry groups. Ideally, they would help combine the superior cold hardiness, plant architecture, and yield of the eastern materials with the superior fruit quality of the trailing blackberry. 
In $1999, R$. ursinus was used as the maternal parent in some wide crosses with $R$. corchorifolius L.f., R. niveus Thunb., R. multibracteatus A. Leveille \& Vaniot, $R$. sachalinensis A. Leveille, and $R$. leucodermis Douglas ex Torrey \& A. Gray, and with the semierect blackberries. These diploid or tetraploid species represent the Ideaobatus, Malachobatus, and Rubus subgenera. Crosses appeared successful with $R$. multibracteatus, $R$. sachalinensis, $R$. leucodermis, and the eastern blackberries. When these seedlings are grown out, we will be able to determine whether they are truly hybrids. Apparently, the high ploidy level of $R$. ursinus can be used to bring very diverse Rubus germplasm into a common breeding pool that will be useful in our breeding program.

\section{CONCLUSIONS}

Our $R$. ursinus project has nearly completed the full cycle of the basic objectives. Utilizing field collection and accessions from the Germplasm Repository system, we have collected a broad range of the primary species in the background of the cultivated trailing blackberry. This germplasm has been characterized for a number of traits in the greenhouse and in the field, and ploidy levels have been determined. A diverse group of selections representing the ranges of horticultural diversity and geography have been identified and crossed with advanced plant materials. Selections have been made that may have sufficient quality to become cultivars. Additionally, these selections will serve as parents for new cultivars or may serve as genetic bridges between species and subgenera. In this process, new or improved traits have been incorporated into advanced breeding material. Now that this collection has been refined and characterized, the most exciting work of further crossing this material and looking at new populations lies before us.

\section{Literature Cited}

Anderson A.K. and C.E. Finn. 1995a. Variation in reproductive traits of western trailing blackberry (Rubus ursinus) in the Pacific Northwest. HortScience 30:833.

Anderson, A.K. and C.E. Finn. 1995b. Morphological variation in western trailing blackberry (Rubus ursinus) in the Pacific Northwest. HortScience 30:767.

Anderson, A.K. and C.E. Finn 1996. Geographical influences on morphological variation in Rubus ursinus subsp. macropetalus. HortScience 31:609.

Brown, S.W. 1943. The origin and nature of variability in the Pacific Coast blackberries (Rubus ursinus Cham. and Schlecht. and R. lemurum sp. nov.). Amer. J. Bot. 30:686-697.

Clark, J.R., 1992. Blackberry production and cultivars in North American east of the Rocky Mountains. Fruit Var. J. 46:217-222.

Finn, C.E. and R.R. Martin. 1996. Distribution of tobacco streak, tomato ringspot, and raspberry bushy dwarf viruses in Rubus ursinus and $R$. leucodermis collected from the Pacific Northwest. Plant Dis. 80:769-772.

Finn, C., B. Strik, and F.J. Lawrence. 1997. 'Marion' trailing blackberry. Fruit Var. J. 51:130-133.

Hall, H.K. 1990. Blackberry breeding. Plant Breed. Rev. 8:249-312.

Hitchcock, C.L. and A. Cronquist. 1973. Flora of the Pacific Northwest. Univ. of Washington Press, Seattle.

Jennings, D. L. 1988. Raspberries and blackberries: Their breeding diseases and growth. Academic Press, London.

Meng, R. 1999. Determining ploidy level and nuclear DNA content in Rubus by flow cytometry. MS Thesis, Dept. of Horticulture, Oregon State Univ.

National Agricultural Statistics Service-Oregon Agricultural Statistics Service. 1999. 1998 Berry production down 3 percent. Natl. Agr. Stat. Serv.Oregon Agr. Stat. Serv., Portland.

SAS Institute Inc. 1995. The SAS system for Windows, v. 6.12. SAS Inst., Cary, N.C.

Strik, B., J. Mann, and C. Finn. 1996. Percent drupelet set varies among blackberry genotypes. J. Amer. Soc. Hort. Sci. 121:371-373.

Thompson, M.M. 1995a. Chromosome numbers of Rubus species at the National Clonal Germplasm Repository. HortScience 30:1447-1452.

Thompson, M.M. 1995b. Chromosome numbers of Rubus cultivars at the National Clonal Germplasm Repository. HortScience 30:1453-1456.

Thompson, M.M. 1997. Survey of chromosome numbers in Rubus (Rosaceae: Rosoideae). Ann. Missouri Bot. Garden 84:129-165.

Waldo, G.F. 1950. Breeding blackberries. Oregon Agr. Expt. Sta. Bul. 475.

Waldo, G. 1957. The Marion blackberry. Circ. of Inf. 571. Oregon State College, Corvallis.

Waldo, G.F. 1968. Blackberry breeding involving native Pacific coast parentage. Fruit Var. Hort. Dig. 22:3-7.

Waldo, G.F. 1977. 'Thornless Evergreen'—Oregon's leading blackberry. Fruit Var. J. 31:26-30. 